【Transaction】

\title{
Development of Polylactide Fibers Consisting of Highly Oriented Stereocomplex Crystals Utilizing High-Speed Bicomponent Melt Spinning Process
}

\author{
Nanjaporn Roungpaisan, Wataru Takarada, and Takeshi Kikutani\# \\ Department of Materials Science and Engineering, School of Materials and Chemical Technology, Tokyo Institute of Technology, \\ 2-12-1, O-okayama, Meguro-ku, Tokyo 152-8550, Japan
}

\begin{abstract}
With the aim of producing polylactide fibers consisting of highly oriented stereo-complex (SC) crystals, high-speed bicomponent melt spinning of the islands-in-the-sea (I/S) fibers consisting of poly(L-lactide) (PLLA) and poly(D-lactide) (PDLA) as the sea and island components, respectively, was performed. For comparison, bicomponent spinning of the core-sheath $(\mathrm{C} / \mathrm{S})$ fibers consisting of PLLA and PDLA as the sheath and core components was also carried out. Structure analysis of the C/S fibers revealed that the orientationinduced crystallization of the higher molecular weight component, PLLA, started from the take-up velocity of around 4 or $5 \mathrm{~km} / \mathrm{min}$, whereas there was a significant orientation relaxation of the lower molecular weight component, PDLA, with the further increase of take-up velocity up to $10 \mathrm{~km} / \mathrm{min}$. After the on-set of orientation-induced crystallization, development of only homo-crystals was confirmed through the wide-angle X-ray scattering analysis. On the other hand, through the differential scanning calorimetry (DSC) of the I/S fibers, along with the melting peak of homo-crystals, distinct melting peak of the SC crystals was observed. This result suggested the mutual diffusion of PLLA and PDLA molecules during the DSC analysis. Based on these results, post-annealing of the as-spun fibers was attempted at the temperatures of 120 and $190{ }^{\circ} \mathrm{C}$, considering the melting temperatures of the homo and SC crystals of 160 and $220{ }^{\circ} \mathrm{C}$. It was found that the high -speed spun I/S fibers could maintain their shapes after the annealing at $190{ }^{\circ} \mathrm{C}$ under constant length condition if the orientation-induced crystallization proceeded in the spinning process. After the annealing, fibers consisting of a large amount of highly oriented SC crystals was formed successfully, indicating that the diameter of the island fibers was small enough for the efficient mutual diffusion of the PLLA and PDLA molecules in the fiber cross-section.
\end{abstract}

(Received 15 July, 2019; Accepted 26 July, 2019)

\section{Introduction}

Among various bio-based polymers, polylactides have been attracting attention in the field of sustainable materials because of its versatility from the viewpoints of the plentiful resources for polymer production and the adaptability for melt processing. For example, polymerization of polylactide starts from lactide monomers, which can be obtained easily from various renewable natural resources, i.e. corn, potato, rice etc. In addition, various polymer processing technologies such as extrusion, injection molding, compression molding can be adopted for manufacturing variety of polylactide products. This is mainly because of its high glass transition temperature in comparison with other aliphatic polyesters [1].

Because of the presence of asymmetric carbons in its main chain, polylactides can be optically active. The polymer consisting of the isomers of only left hand (or right hand) conformation is poly(L-lactide) (PLLA) (or poly(D-lactide) (PDLA)) [2,3]. In the processing of PLLA and PDLA, basic homo-crystals, $\alpha-, \beta$-, and $\gamma$-form crystals, can be developed depending on the processing conditions [4-12]. Melting temperature of the homo-crystals is about $150-170{ }^{\circ} \mathrm{C}$, which varies depending on the crystalline form, optical purity, and higher order structure. 
Most of the green polymers have been developed with the purpose of replacing conventional olefin polymers such as polyethylene and polypropylene (PP), however their low melting temperatures sometimes cause the limitation of applicability. Melting temperature of the homo-crystals of polylactide is similar to that of PP. A technology for the improvement of the thermal properties of polylactides addressed in many literatures [3,13-18] is the preparation of racemic polylactide by mixing PLLA and PDLA molecules through the solution or melt mixing method to attain a new crystal form, i.e. stereo-complex- (SC-) crystal. Melting temperature of the SC-crystals is about 60 degrees higher than those of the homo-crystals.

It is well known that the formation of SC-crystals from the racemic blend of PLLA and PDLA is not straightforward. In order to acquire enough improvement in the thermal and mechanical properties of the products, amount of the SC-crystals as well as their orientation in the products need to be controlled. There exists a competitive crystallization behavior as well as complicated transformation behavior between the homo- and SC-crystals. Particularly, effect of pre-orientation in amorphous phase on the formation of oriented homo- and SCcrystals [19], effect of molecular weight on the preferred formation of SC-crystals [20], and influence of the melt memory effect for the formation of homocrystals after the formation of SC-crystals [21] etc. have been reported.

On the other hand, for the enhanced formation of the SC-crystals, several techniques have been investigated from the viewpoint of molecular and material design. For instance, addition of soft-segment phases such as polyethylene glycol block to increase molecular movement was found to promote the couple formation of the two different polylactide isomers [22-26]. In contrast, reaction for chemical cross-linking between two enantiomeric phases in amorphous state by adding a small amount of crosslinker was utilized to decrease phase reformation during the melt blending [27]. A star-locking shapes of stereo-complex structure was adopted to enhance inter-molecular locking, which lead to the formation of structure with stronger memory effect and prevents reformation into original structure (homo-crystal) [28]. Designing of PLLA-block-copolymer has promoted the formation of structure with high content of SCcrystals compared to linear structures of PLLA [3, 28-
30].

There are several obstacles for promotion of the formation SC-crystal in a single-step melt processing. Therefore, addition of annealing process is normally necessary for improving the yield of SC-crystals [16, 31-33]. In addition, reduction of molecular weight is anticipated in the direct melt processing of the enantiomeric blend of PLLA and PDLA because melting temperature of the SC-crystal is closer to the thermal degradation temperature of polylactides [34].

One successful study was reported by Takasaki et al [13], in which racemic polylactide was used as the starting material and fibers were prepared through the high-speed melt spinning process. Through this research, it was revealed that the development of highly-oriented SC-crystal could be promoted by applying high elongational stress and enhancing the orientation induced crystallization. Selective formation of the SC-crystal is because of sufficiently high crystallization temperature in the process. However, they found that even though thermal property of racemic fiber was improved, mechanical property was limited when compared with neat polylactide fibers.

In this research, production of polylactide fibers containing a large amount of highly oriented SCcrystals was attempted introducing a new concept of utilizing the high-speed bicomponent melt spinning of islands-in-the-sea (I/S) fibers, in which PLLA and PDLA were used as the sea and island components, respectively. If the size of islands is small enough and the number of islands is large enough, development of enough amount of SC-crystals through the mutual diffusion of the PLLA and PDLA molecules in the fiber cross-section can be expected. For better understanding of the structure development behavior of individual components in the high-speed bicomponent melt spinning process, core-sheath $(\mathrm{C} / \mathrm{S})$ fibers, in which PLLA and PDLA were used as the sheath and core components respectively, were also prepared.

\section{Experimental}

\subsection{Fiber preparation}

\subsubsection{Materials}

Two types of optically active polylactide, poly(Llactide) (PLLA) and poly(D-lactide) (PDLA) with the optical purity higher than $99.5 \%$ were supplied by Corbion, Netherlands, and used in this research. Melt 
flow rates of the PLLA and PDLA were 16 and $25 \mathrm{~g}$ / 10 min, respectively. Before the melt spinning experiment, all polylactide pellets were dried at $100^{\circ} \mathrm{C}$ for $24 \mathrm{~h}$ under vacuum.

\subsubsection{Equipment for bicomponent high-speed melt spinning}

Bicomponent fibers were produced by extruding the melts of PLLA and PDLA using two different extrusion systems. Each extrusion system consisted of a single-screw extruder and a gear pump. The two extrusion systems were attached to a spinning head, in which a spinning pack for the production of coresheath $(\mathrm{C} / \mathrm{S})$ or islands-in-the-sea (I/S) bicomponent fibers was installed. Schematics of the spinning packs are shown in Fig. 1. The spinning pack for the I/S fibers can produce fibers containing 1519 islands in its cross-section. Spinnerets with a single circular hole of $1.0 \mathrm{~mm}$ diameter were used for the production of $\mathrm{C} / \mathrm{S}$ and I/S fibers. A high-speed winder with the maximum take-up velocity of $10 \mathrm{~km} / \mathrm{min}$ was placed at about $3.5 \mathrm{~m}$ below the spinning head. (a) $\mathrm{C} / \mathrm{S}$ spinning pack
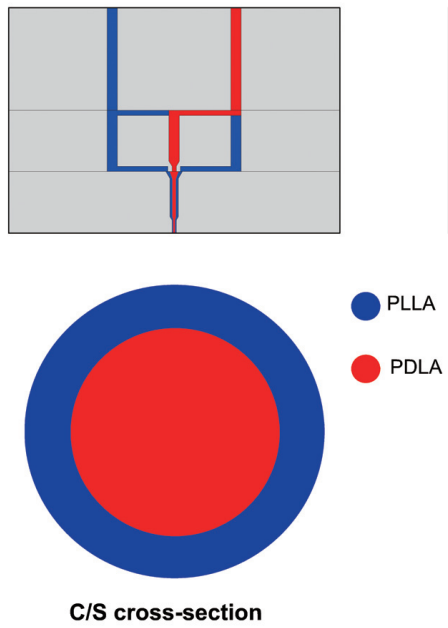

(b) I/S spinning pack
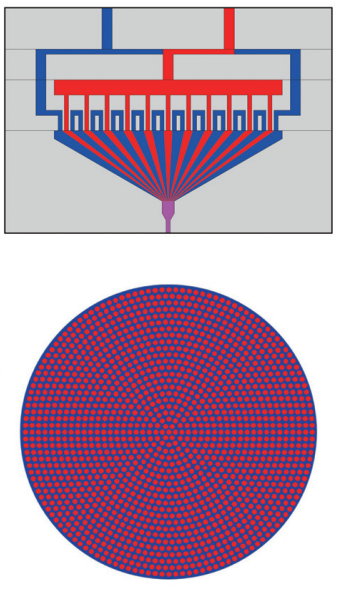

I/S cross-section
Fig. 1 Schematics of the spinning packs for production of core-sheath $(\mathrm{C} / \mathrm{S})$ and islands-inthe-sea (I/S) fibers. Cross sectional configurations of the $\mathrm{C} / \mathrm{S}$ and I/S fibers are also shown.

\subsubsection{Spinning conditions}

The $\mathrm{C} / \mathrm{S}$ and I/S fibers were prepared using the PLLA as the sheath or sea component and the PDLA as the core or island component, respectively. The extrusion temperature was set to 230 or $250{ }^{\circ} \mathrm{C}$. The total through-put rate was $5.0 \mathrm{~g} / \mathrm{min}$ where that of each component was kept at $2.5 \mathrm{~g} / \mathrm{min}$. For each extrusion condition, take-up velocity was increased from $1.0 \mathrm{~km} / \mathrm{min}$ to the highest velocity where spinning could be attained with the interval of $1.0 \mathrm{~km} /$ $\min$

\subsubsection{On-line diameter measurement}

Spin-line diameter was measured during the spinning process using a back-illumination type diameter monitor (model 460/A 10, Zimmer OHG). The measurement was carried out by changing the distance from the spinneret from 10 to $330 \mathrm{~cm}$ with the interval of $10 \mathrm{~cm}$.

\subsubsection{Post annealing process}

Post annealing of the as-spun fibers was conducted using a heating oven. Bundles of as-spun fibers were fixed to a holder to keep their lengths constant. The annealing temperatures of 120 and $190{ }^{\circ} \mathrm{C}$ were adopted. It should be noted that melting temperatures of homo- and SC crystals are around 160 and $220^{\circ} \mathrm{C}$. In other words, annealing temperature $190{ }^{\circ} \mathrm{C}$ was higher than the melting temperature of the homo-crystals, but lower than that of the SCcrystals. After the annealing of 1 hour, the holder with the fiber samples was taken out from the oven and cooled down to room temperature.

\subsection{Characterization of fibers}

\subsubsection{Observation of fiber cross-section}

Cross-sections of the free fall sample and as-spun fibers were prepared and observed under an optical microscope (OM, BX 53, Olympus).

\subsubsection{Wide-angle X-ray scattering measurement}

Wide-angle X-ray scattering (WAXS) measurement of the fiber samples was performed by using an X-ray source equipped with a CCD detector (Rigaku). Samples for the WAXS measurement were carefully prepared by aligning the fibers to a controlled thickness on a holder. The nickel filtered $\mathrm{CuK} \alpha \mathrm{X}$-ray beam generated at $60 \mathrm{kV}$ and $45 \mathrm{~mA}$ was irradiated to the samples to obtain two-dimensional WAXS patterns.

\subsubsection{Birefringence measurement}

Refractive indices of the fibers in the parallel and perpendicular directions with respect to the fiber axis were measured using an interference microscope (Carl Zeiss Jena) equipped with a polarizing filter. Birefringence was obtained as the difference of parallel and perpendicular refractive indices. Immersion liquids with refractive indices of 1.46 and 1.47 were found to be appropriate for obtaining proper interference fringe patterns under the interference microscope. For the measurement of $\mathrm{C} / \mathrm{S}$ fibers, the refractive indices of the core and sheath parts were analysed separately based on the method described elsewhere [35-37]. For the I/S fibers, only 
averaged birefringence of island and sea parts could be obtained because diameter of the island was equivalent to the wave-length of light.

\subsubsection{Differential scanning calorimetry (DSC)}

The thermal property of fibers was analysed by using a differential scanning calorimeter (DSC, Q-100, TA instruments). About 5-10 mg of fiber sample cut to small pieces was encapsulated in an aluminium DSC pan. The DSC measurement was carried out from room temperature to $250{ }^{\circ} \mathrm{C}$ at a heating rate of $5{ }^{\circ} \mathrm{C} / \mathrm{min}$ applying purging nitrogen gas of $50 \mathrm{~mL} / \mathrm{min}$.

\section{Results and discussion}

\subsection{Spinning behavior}

For the high-speed melt spinning of $\mathrm{C} / \mathrm{S}$ fibers with the extrusion temperatures of 230 and $250{ }^{\circ} \mathrm{C}$, fiber samples could be obtained up to the take-up velocity of $10 \mathrm{~km} / \mathrm{min}$, which is the maximum velocity of the winder used in this experiment. Spinnability was slightly lower for the spinning of I/S fibers. Fiber samples could be obtained up to the take-up velocities of 7 and $9 \mathrm{~km} / \mathrm{min}$ for the extrusion temperatures of 230 and $250^{\circ} \mathrm{C}$, respectively.

Diameter profiles of the spin-line for the spinning of $\mathrm{C} / \mathrm{S}$ fibers with the extrusion temperatures of 230 and $250{ }^{\circ} \mathrm{C}$ and those for the spinning of $\mathrm{I} / \mathrm{S}$ fibers with the extrusion temperature of $250^{\circ} \mathrm{C}$ are shown in Fig. 2. Measurement for the $\mathrm{I} / \mathrm{S}$ fibers at the extrusion temperature of $230{ }^{\circ} \mathrm{C}$ was difficult because spin-line breakage occurred frequently. Since the total through-put rate was kept constant at $5.0 \mathrm{~g} / \mathrm{min}$, final fiber diameter decreased with the increase of take-up velocity.

Ordinary gradual thinning of the spin-line was observed at a low take-up velocity of $1 \mathrm{~km} / \mathrm{min}$. With the increase of take-up velocity, thinning tended to concentrate to down-stream, i.e. near the solidification point, whereas the thinning behavior was almost similar in the up-stream, i.e. up to the distance from the spinneret of $100 \mathrm{~cm}$. This is the characteristics of the high-speed spin-line of relatively low viscosity materials. When the take-up velocity reached $4 \mathrm{~km} /$ min, the spin-line started to show the sudden reduction of diameter, which is called neck-like deformation. After the starting of the neck-like deformation, the solidification point shifted to upstream and the draw-down ratio at the neck-like deformation increased with the increase of take-up velocity. It is generally recognized that the neck-like deformation corresponds to the occurrence of orientation-induced crystallization [38], and the shift of the position of neck-like deformation toward upstream under the constant through-put rate condition corresponds to the increase in crystallization temperature.

Comparing the results for the $\mathrm{C} / \mathrm{S}$ fiber spinning with the extrusion temperatures of 230 and $250{ }^{\circ} \mathrm{C}$, it can be recognized that the neck-like deformation occurred at the position closer to the spinneret and its profile became steeper for the lower extrusion temperature. This can be due to the lower temperature of the spin-line at the same position and/ or the enhancement of crystallization caused by
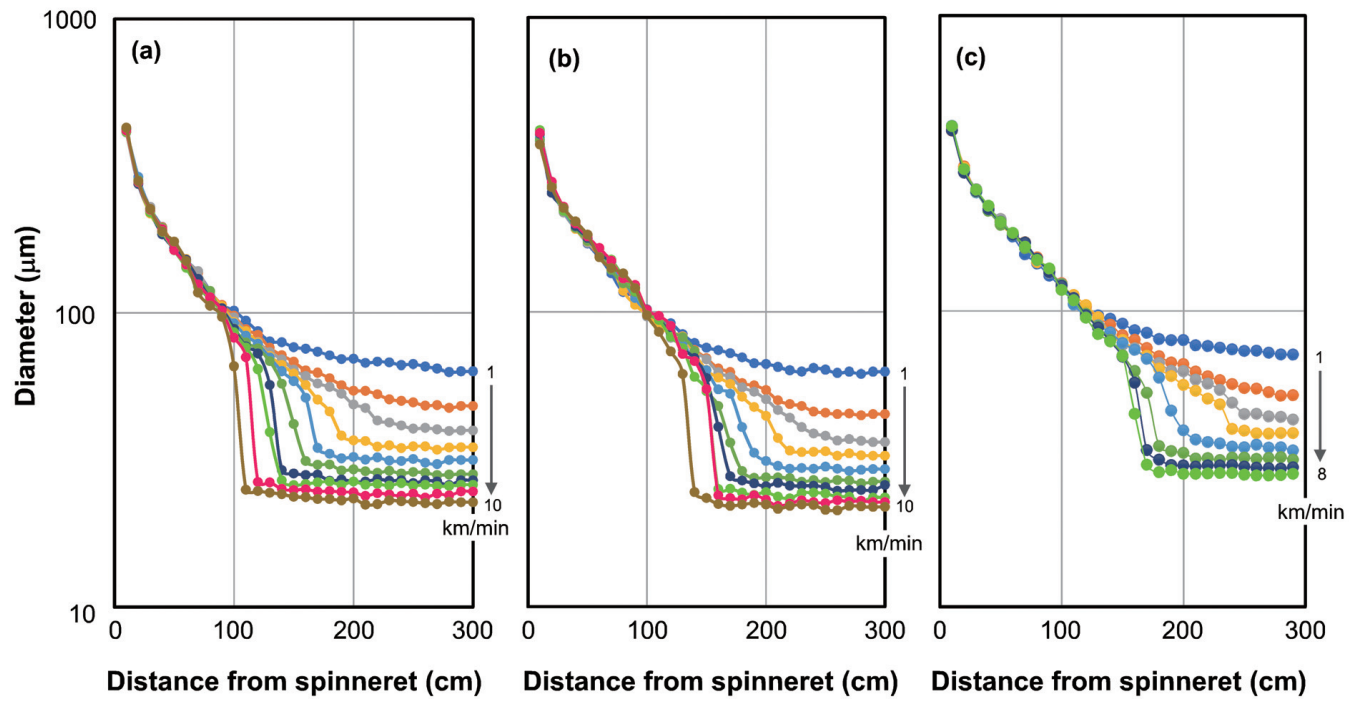

Fig. 2 Diameter profiles of the spin-line measured at various take-up velocities. (a) and (b) are for the C/S spinning with the extrusion temperatures of 230 and $250{ }^{\circ} \mathrm{C}$, respectively. (c) is for the I/S spinning with the extrusion temperature of $250{ }^{\circ} \mathrm{C}$. 
higher spin-line stress. On the other hand, comparing the $\mathrm{C} / \mathrm{S}$ and $\mathrm{I} / \mathrm{S}$ fiber spinnings at the extrusion temperature of $250{ }^{\circ} \mathrm{C}$, it was found that the thinning behavior in the up-stream was slightly milder and the position of neck-like deformation was slightly further from the spinneret for the I/S spinning. In the $\mathrm{C} / \mathrm{S}$ fiber, the higher viscosity component PLLA was placed at the sheath, whereas the PLLA and PDLA components were evenly distributed in the fiber cross -section in the I/S fiber. Because of the generation of temperature distribution in the cross-section during the spinning process, crystallization of PLLA could be promoted in the $\mathrm{C} / \mathrm{S}$ spin-line, which led to the shift of the position of neck-like deformation closer to the spinneret.

\subsection{Structure of as-spun fibers}

\subsubsection{Fiber cross-section}

Photographs of the cross-section of the $\mathrm{C} / \mathrm{S}$ and I/S as-spun fibers, and the free fall sample of I/S spinning are shown in Fig. 3. As described previously, fiber diameter decreased with the increase of take-up velocity. For the $\mathrm{C} / \mathrm{S}$ fibers, boundary between the core and sheath components was not clear at a low take-up velocity of $1 \mathrm{~km} / \mathrm{min}$, however, distinct boundary was observed for the fibers prepared at higher take-up velocities. On the other hand, for the $\mathrm{I} / \mathrm{S}$ fibers, the islands could not be identified clearly in the cross-section of the as-spun fibers because of their small diameters. Nevertheless, from the photograph of the cross-section of free-fall sample with the diameter of around $176 \mu \mathrm{m}$, it was confirmed that the islands-in-the-sea configuration was successfully fabricated in the fiber cross-section.

\subsubsection{WAXS patterns}

WAXS patterns of high-speed spun $\mathrm{C} / \mathrm{S}$ and I/S fibers are shown in Fig. 4 and 5, respectively. As-spun fibers prepared at the take-up velocity of $1 \mathrm{~km} / \mathrm{min}$ showed almost isotropic amorphous halo. With the increase of take-up velocity, amorphous halo tended to concentrate on the equator, and distinct crystalline reflections of highly oriented $\alpha$-form crystals could be observed at higher take-up velocities. It should be noted that for the $\mathrm{C} / \mathrm{S}$ fibers with the extrusion temperature of $230{ }^{\circ} \mathrm{C}$, crystalline reflections started to appear from $4 \mathrm{~km} / \mathrm{min}$, whereas for the $\mathrm{C} / \mathrm{S}$ spinning of $250{ }^{\circ} \mathrm{C}$ and the I/S spinning of both 230 and $250{ }^{\circ} \mathrm{C}$, only amorphous halo was observed at 4 $\mathrm{km} / \mathrm{min}$, and the crystalline reflections started to appear from $5 \mathrm{~km} / \mathrm{min}$. These results are in accordance with the neck-like deformation behavior of the spin-line shown in Fig. 2.

\subsubsection{Birefringence}

Variation of birefringence with the take-up velocity for the $\mathrm{C} / \mathrm{S}$ and I/S fibers is shown in Fig. 6 . In general, birefringence increased with the increase of take-up velocity in low take-up velocity region. For the $\mathrm{C} / \mathrm{S}$ fibers, birefringence of the sheath part increased suddenly from 4 and $5 \mathrm{~km} / \mathrm{min}$ and that of the core part reached a maximum at around 5 and 6 $\mathrm{km} / \mathrm{min}$ and then decreased for the extrusion temperatures of 230 and $250{ }^{\circ} \mathrm{C}$, respectively. For the $\mathrm{C} / \mathrm{S}$ fibers with the extrusion temperature of $230{ }^{\circ} \mathrm{C}$, birefringence of the core component was almost zero at the take-up velocities of 8,9 and $10 \mathrm{~km} / \mathrm{min}$.

Similar behavior was reported for the high-speed melt spinning of the $\mathrm{C} / \mathrm{S}$ fibers of low and high

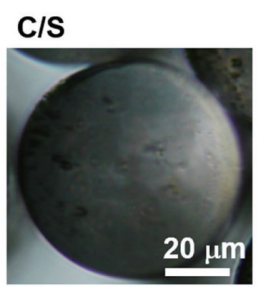

$1 \mathrm{~km} / \mathrm{min}$

I/S

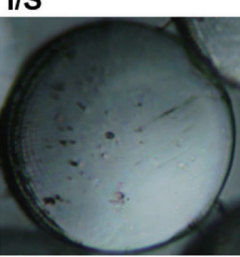

$1 \mathrm{~km} / \mathrm{min}$

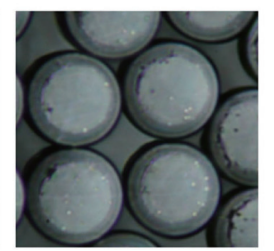

$5 \mathrm{~km} / \mathrm{min}$

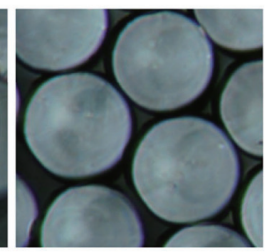

$5 \mathrm{~km} / \mathrm{min}$

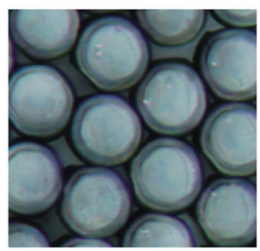

$10 \mathrm{~km} / \mathrm{min}$

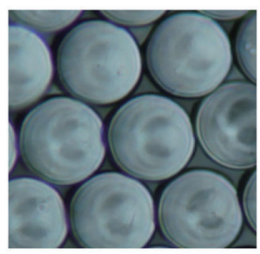

$7 \mathrm{~km} / \mathrm{min}$
I/S

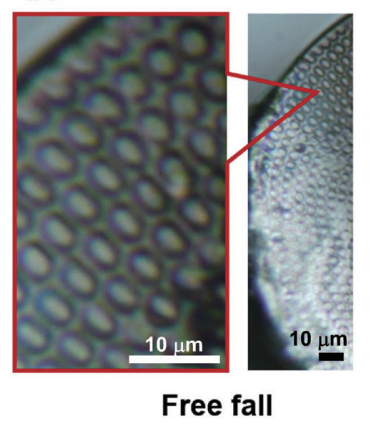

Free fall

Fig. 3 Optical photo-micrographs of the cross-section of the $\mathrm{C} / \mathrm{S}$ and $\mathrm{I} / \mathrm{S}$ as-spun fibers prepared at three different take-up velocities. Cross-section of the free-fall sample of I/S fiber is also shown to prove the formation of islands-in-the-sea configuration. 


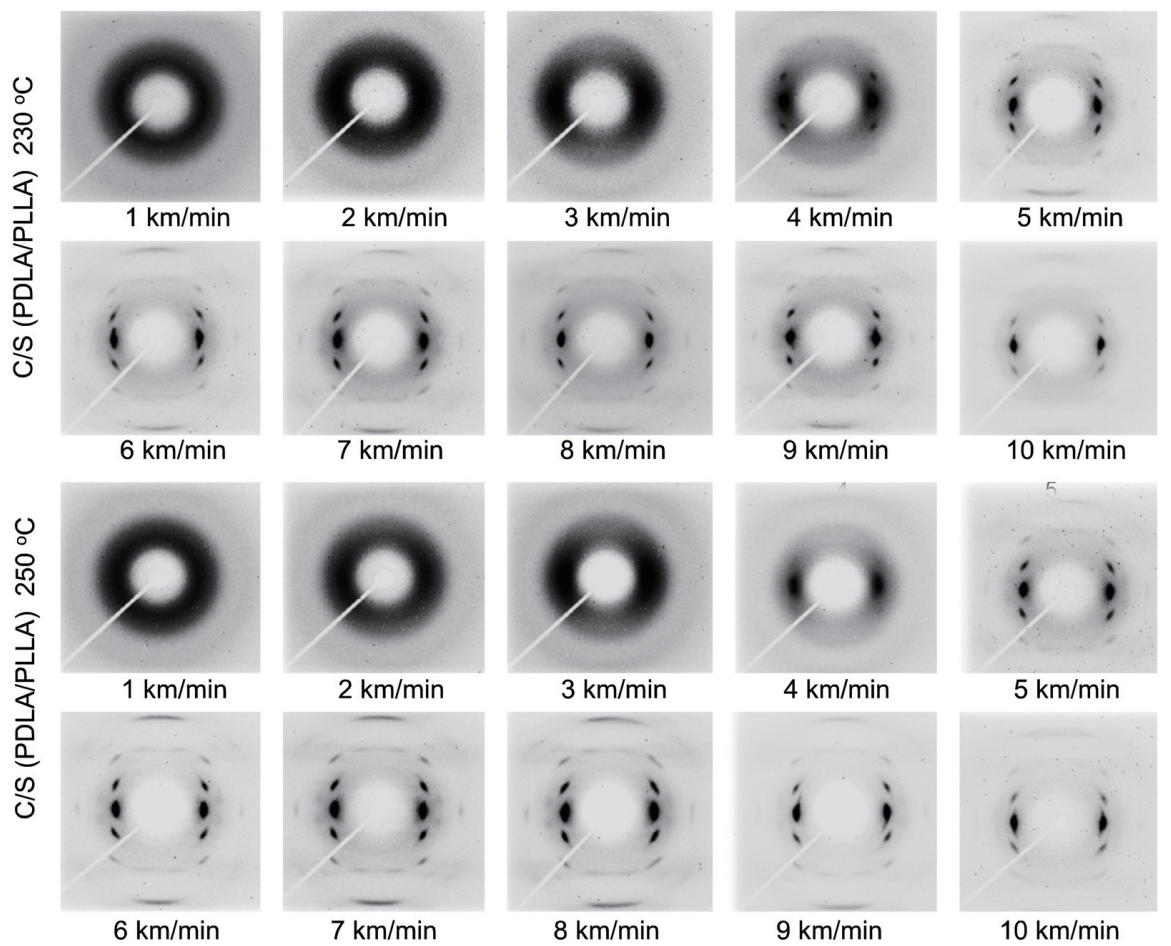

Fig. 4 WAXS patterns of the $\mathrm{C} / \mathrm{S}$ as-spun fibers prepared at various take-up velocities. Results for the fibers prepared at the extrusion temperatures of 230 and $250{ }^{\circ} \mathrm{C}$ are shown.

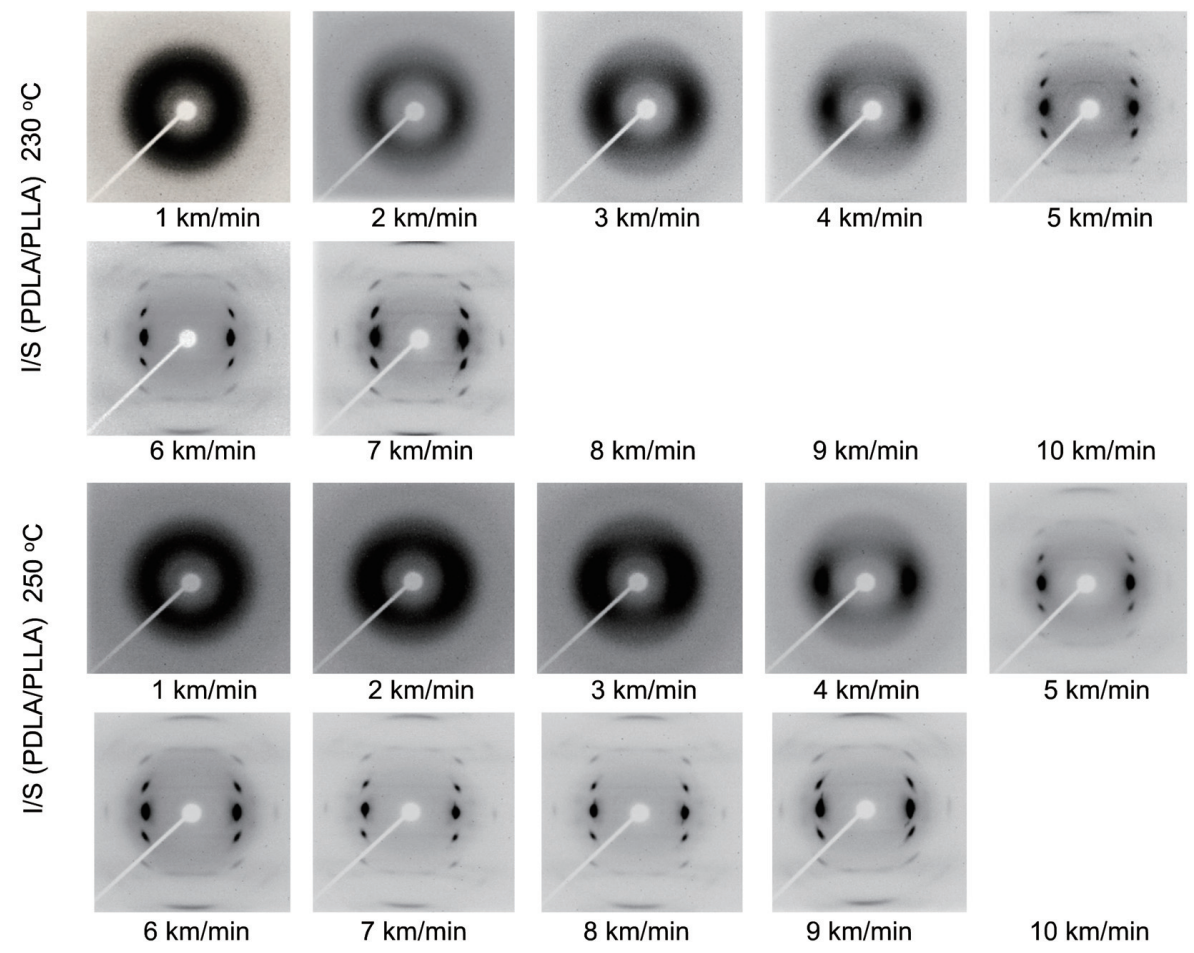

Fig. 5 WAXS patterns of the I/S as-spun fibers prepared at various take-up velocities. Results for the fibers prepared at the extrusion temperatures of 230 and $250{ }^{\circ} \mathrm{C}$ are shown.

molecular weight poly(ethylene terephthalate)s, and the mechanism of structure development was interpreted [36]. In this experiment molecular weight of the sheath component, PLLA, was higher than that of the core component, PDLA. The tensile stress applied in the spin-line to the higher molecular weight component was higher. Accordingly, the orientation- induced crystallization could start from a lower takeup velocity for the sheath component, PLLA. When the crystallization of the sheath component occurred in the cooling process of the spin-line at a temperature higher than the glass transition temperature (Tg), orientation relaxation of the lower molecular weight component, PDLA, could proceed until the spin-line 

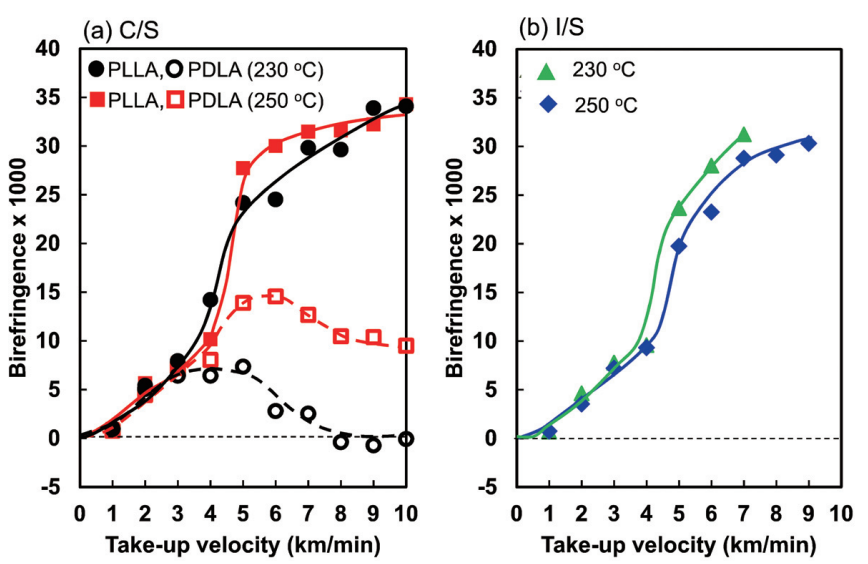

Fig. 6 Variations of birefringence with take-up velocity for (a) sheath (PLLA) and core (PDLA) components of the $\mathrm{C} / \mathrm{S}$ as-spun fibers prepared with the extrusion temperatures of 230 and $250{ }^{\circ} \mathrm{C}$, and for (b) I/S fibers prepared with the extrusion temperatures of 230 and $250{ }^{\circ} \mathrm{C}$. For figure (a), closed and open symbols correspond to the PLLA and PDLA, respectively, whereas red and black symbols correspond to the extrusion temperatures of 230 and $250^{\circ} \mathrm{C}$, respectively.

temperature reached the $\mathrm{Tg}$. With the increase of take - up velocity, the orientation - induced crystallization of PLLA tended to occur at higher temperatures, as evidenced from the position of necklike deformation in the spin-line shown in Fig. 2, and eventually orientation-relaxation of the PDLA proceeded more significantly.

For the extrusion temperature of $230{ }^{\circ} \mathrm{C}$, the orientation-induced crystallization started from $4 \mathrm{~km} /$ min. Because of the enhancement of the preferred crystallization of the PLLA, there was a significant reduction of birefringence of PDLA. Distinct difference between the birefringence of core components was observed between two different extrusion temperatures. Higher birefringence of the core part for the extrusion temperature of $250{ }^{\circ} \mathrm{C}$ suggested that the crystallization behavior of the core component was different in comparison with the result for the $230{ }^{\circ} \mathrm{C}$ spinning. Presumably, orientation -induced crystallization of both PLLA and PDLA components started to occur at $5 \mathrm{~km} / \mathrm{min}$. Nevertheless, these behaviors of birefringence variation agreed well with the result of the WAXS measurement.

On the other hand, for the spinning of I/S fibers with the extrusion temperatures of 230 and $250{ }^{\circ} \mathrm{C}$, birefringence showed steep increases from 4 to $5 \mathrm{~km} /$ min. These behavior also corresponded to the starting of orientation-induced crystallization, where the structure development was promoted by lowering the extrusion temperature.

There was a certain similarity in the variation of birefringence with the increase of take-up velocity for the $\mathrm{C} / \mathrm{S}$ and $\mathrm{I} / \mathrm{S}$ spinnings. If the structure developments of the island and sea components in the I/S spinning were identical with those of the core and sheath components in the $\mathrm{C} / \mathrm{S}$ spinning, respectively, averaged birefringence of the core and sheath components supposed to be similar to the birefringence of the I/S fibers. However, birefringence of the I/S fibers was distinctively higher than the averaged values, and the difference was larger for the extrusion temperature of $230{ }^{\circ} \mathrm{C}$. The reason for this discrepancy is not clear at this moment. Possible reasons are the enhanced mutual diffusion of PLLA and PDLA molecules occurring in the melt spinning process for the I/S spinning, which will be discussed in later sections or the effect of form birefringence.

\subsubsection{DSC analysis}

Results of DSC analysis are shown in Fig. 7. For the low speed spun fibers, glass transition, cold crystallization and melting were observed consecutively with the increase of temperature. The cold crystallization temperature gradually decreased with the increase of take-up velocity. This is because of the increase in crystallization rate accompanied by the molecular orientation. Relatively large width of the cold crystallization peak at $2 \mathrm{~km} / \mathrm{min}$ may indicate that the PLLA showed lower cold crystallization temperature than PDLA because of its higher effect of molecular orientation [36], even though distinct birefringence difference between PLLA and PDLA could not be observed at this takeup velocity as shown in Fig. 6.

For the $\mathrm{C} / \mathrm{S}$ spinning with the extrusion temperature of $230{ }^{\circ} \mathrm{C}$, the cold crystallization peak was observed continuously up to the maximum takeup velocity, $10 \mathrm{~km} / \mathrm{min}$. The peak temperature gradually decreased from 1 to $4 \mathrm{~km} / \mathrm{min}$, and then gradually increased with the increase of take-up velocity. For the extrusion temperature of $250{ }^{\circ} \mathrm{C}$, the cold crystallization was less distinct at high take-up velocities. These results are in good accordance with the variations of birefringence of PLLA (sheath) and PDLA (core) components with the take-up velocity shown in Fig. 6.

Interpretation of the melting behavior of high- 
(a) $\mathrm{C} / \mathrm{S} 230^{\circ} \mathrm{C}$

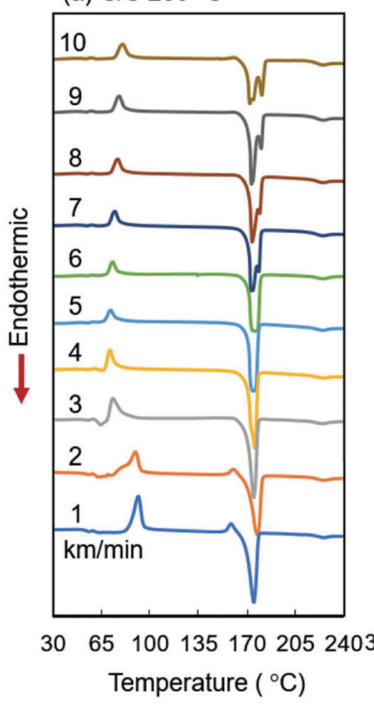

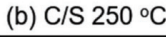

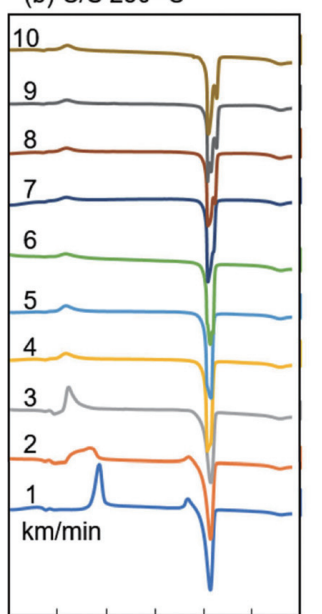

65100135170205
Temperature $\left({ }^{\circ} \mathrm{C}\right)$ (c) $\mathrm{I} / \mathrm{S} 230^{\circ} \mathrm{C}$

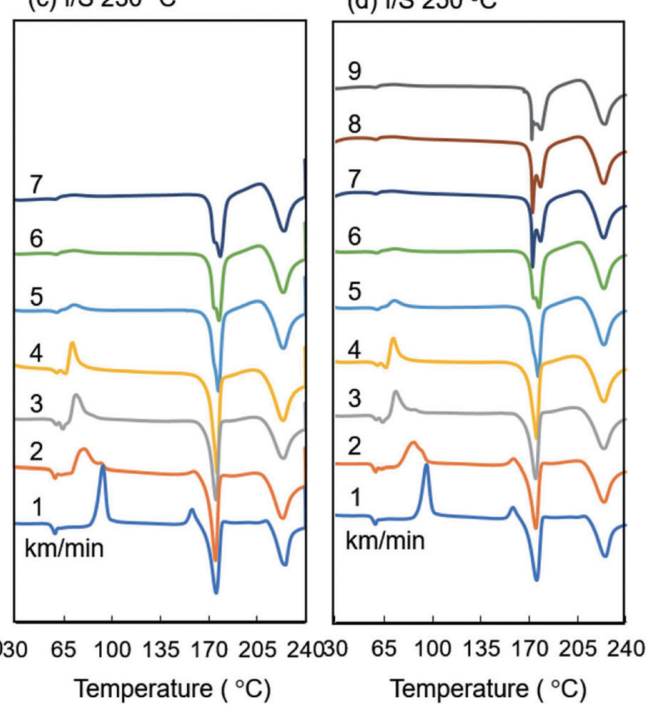

Fig. 7 DSC thermograms of the high-speed spun bicomponent fibers with the cross-sectional configuration and extrusion temperature of (a) $\mathrm{C} / \mathrm{S}, 230^{\circ} \mathrm{C}$, (b) $\mathrm{C} / \mathrm{S}, 250{ }^{\circ} \mathrm{C}$, (c) I/S, $230{ }^{\circ} \mathrm{C}$, and (d) $\mathrm{I} / \mathrm{S}, 250{ }^{\circ} \mathrm{C}$.

speed spun polylactides in the DSC measurement is not straight forward. For both $\mathrm{C} / \mathrm{S}$ and $\mathrm{I} / \mathrm{S}$ bicomponent fibers prepared at high take-up velocities, split of the melting peak was observed, however these results do not necessarily mean that each peak corresponds to the melting of either PLLA or PDLA component. In the DSC analysis of the highspeed spun single component PLLA fibers, it has been reported that melting and recrystallization proceed simultaneously before the appearance of the endothermic melting peak and continue until the perfect melting of the polymer [39]. Appearance of a small exothermic peak before the starting of melting and splitting of the melting peak at high take-up velocities are also known to be accompanied by the simultaneous occurrence of the melting and recrystallization. Formation of the imperfect $\alpha^{\prime}$-form crystals in the melt spinning process makes the melting behavior even more complicated. Detailed analyses of the melting behavior of PLLA and PDLA are necessary for further discussion.

For the I/S fibers, basic characteristics of the thermal behavior were similar to those of the $\mathrm{C} / \mathrm{S}$ fibers, where cold crystallization peak almost disappeared when the take-up velocity reached $5 \mathrm{~km} /$ min as in the case of $\mathrm{C} / \mathrm{S}$ spinning of $250{ }^{\circ} \mathrm{C}$. It should be noted that for all I/S fibers, a new melting peak was clearly observed at around $225{ }^{\circ} \mathrm{C}$, which corresponded to the melting temperature of the SCcrystals. In addition, exothermic peak was also observed clearly before the starting of the new melting peak. As shown in Fig. 5, the low speed spun fibers were in an amorphous state, and the high-speed spun fibers only exhibited crystalline reflections from the $\alpha$-form crystals. Therefore, it was suggested that the SC-crystals were formed in the process of DSC measurement. This means that the mutual diffusion of PLLA and PDLA molecules at the boundary of island and sea components in the I/S fibers proceeded considerably. It was speculated that the effect of mutual diffusion became visible because of the extremely large interface area in this cross-sectional configuration. Re-examining the DSC data for the $\mathrm{C} / \mathrm{S}$ fibers carefully, it was found that a small melting peak of the SC-crystals also existed at around $225^{\circ} \mathrm{C}$.

\subsection{Structure of annealed fibers}

\subsubsection{WAXD patterns}

Results of the DSC measurement of the I/S fibers suggested the occurrence of a large extent of mutual diffusion of the PLLA and PDLA molecules at the interface. To confirm this concept, annealing of the high-speed spun $\mathrm{C} / \mathrm{S}$ and I/S fibers was carried out at 120 and $190^{\circ} \mathrm{C}$ for $1 \mathrm{~h}$ under the fixed-length condition. Annealing at $190{ }^{\circ} \mathrm{C}$ was possible for the I/S fibers whereas it was not possible for the $\mathrm{C} / \mathrm{S}$ fibers because fibers melted and deformed.

WAXS patterns of the $\mathrm{C} / \mathrm{S}$ and $\mathrm{I} / \mathrm{S}$ fibers annealed at $120{ }^{\circ} \mathrm{C}$ are shown in Fig. 8 and 9. For all annealed $\mathrm{C} / \mathrm{S}$ fibers, existence of oriented $\alpha$-form crystals was confirmed. Degree of crystalline orientation increased from 1 to $4 \mathrm{~km} / \mathrm{min}$, and stayed at a high level above this speed. There was no indication of the formation of SC-crystals. For the I/S fibers annealed at $120{ }^{\circ} \mathrm{C}$, crystalline structure was 

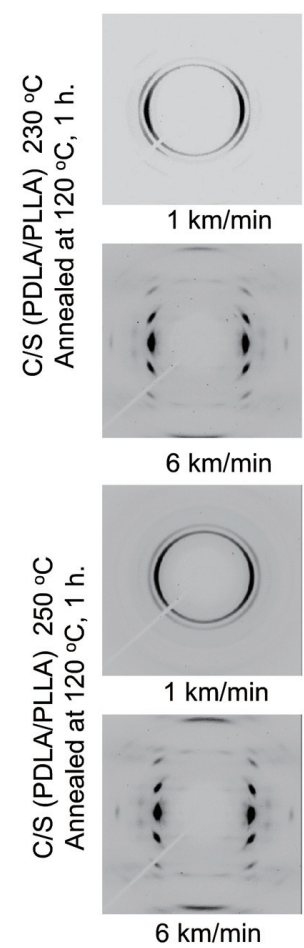

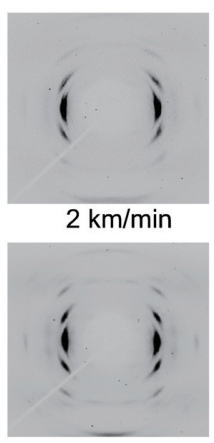

$7 \mathrm{~km} / \mathrm{min}$

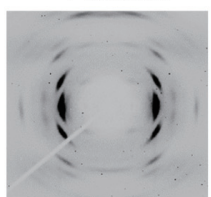

$2 \mathrm{~km} / \mathrm{min}$

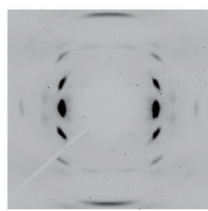

$7 \mathrm{~km} / \mathrm{min}$

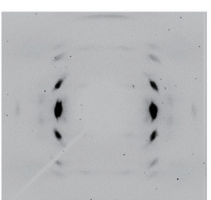

$3 \mathrm{~km} / \mathrm{min}$

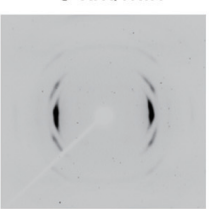

$8 \mathrm{~km} / \mathrm{min}$

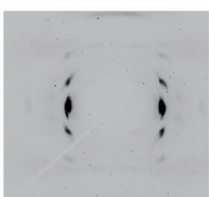

$3 \mathrm{~km} / \mathrm{min}$

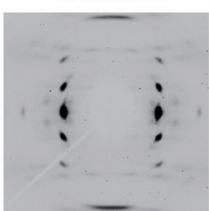

$8 \mathrm{~km} / \mathrm{min}$

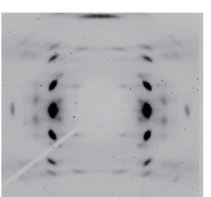

$4 \mathrm{~km} / \mathrm{min}$

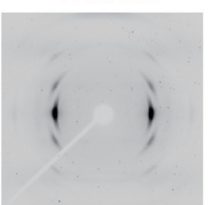

$9 \mathrm{~km} / \mathrm{min}$

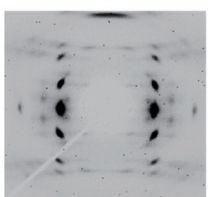

$4 \mathrm{~km} / \mathrm{min}$

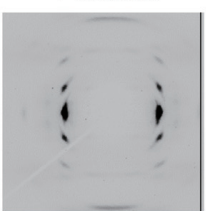

$9 \mathrm{~km} / \mathrm{min}$

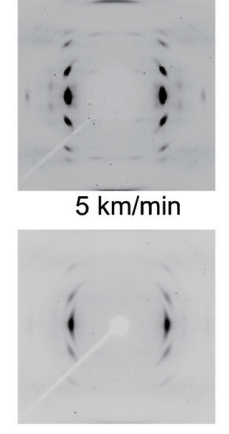

$10 \mathrm{~km} / \mathrm{min}$

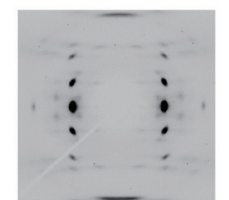

$5 \mathrm{~km} / \mathrm{min}$

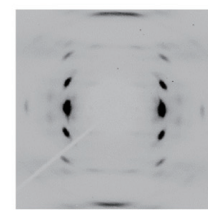

$10 \mathrm{~km} / \mathrm{min}$

Fig. 8 WAXS patterns of the $\mathrm{C} / \mathrm{S}$ fibers after annealing at $120^{\circ} \mathrm{C}$ for one hour. Results for the $\mathrm{C} / \mathrm{S}$ fibers prepared at the extrusion temperatures of 230 and $250^{\circ} \mathrm{C}$ are shown.
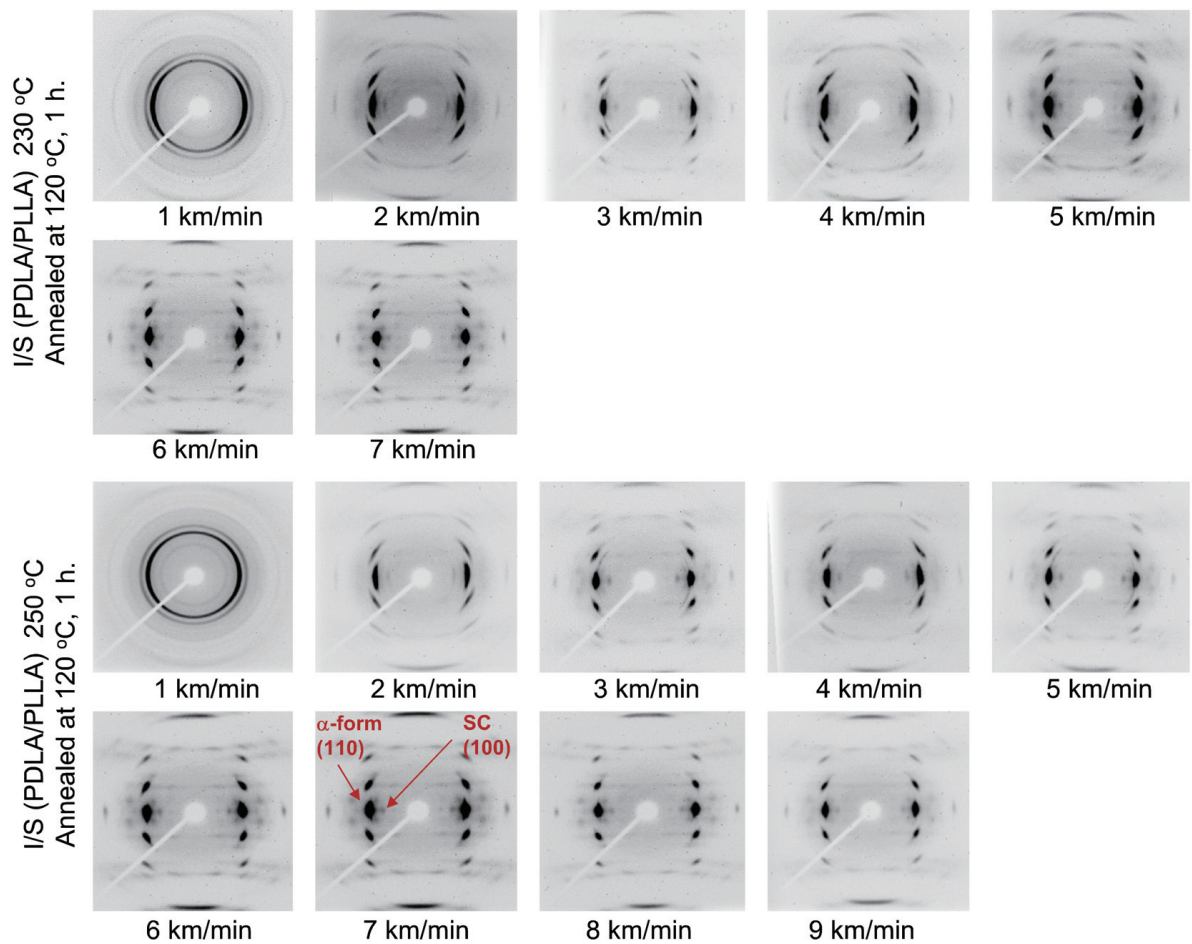

$5 \mathrm{~km} / \mathrm{min}$

Fig. 9 WAXS patterns of the I/S fibers after annealing at $120{ }^{\circ} \mathrm{C}$ for one hour. Results for the I/S fibers prepared at the extrusion temperatures of 230 and $250{ }^{\circ} \mathrm{C}$ are shown.

also dominated by the $\alpha$-form crystals, and its orientation increased with the increase of take-up velocity as in the case of the $\mathrm{C} / \mathrm{S}$ fibers. It was also noted that a new weak crystalline peak of high orientation appeared on the equator in these WAXS patterns. Because the reflection located at a slightly lower diffraction angle, $2 \theta$, in comparison with the distinct $\alpha$-form (110) reflection at $2 \theta$ of $16.7^{\circ}$, this reflection could be assigned to the SC-crystal (100) reflection at $2 \theta$ of $12.0^{\circ}[13,40]$. In other words, coexistence of a small amount of highly oriented SCcrystals was confirmed for all I/S fibers annealed at $120^{\circ} \mathrm{C}$.

When the annealing temperature was raised to 


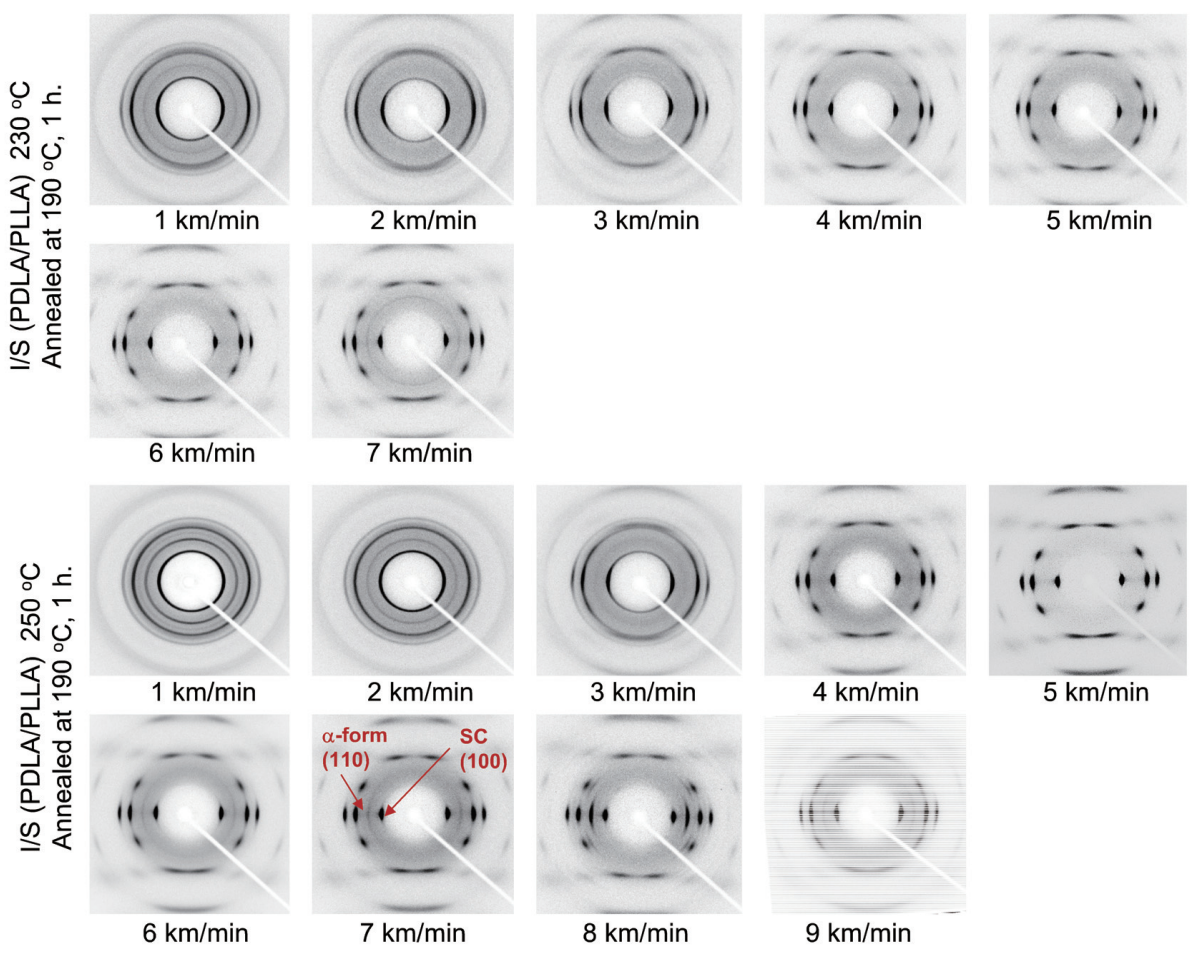

Fig. 10 WAXS patterns of the I/S fibers after annealing at $190{ }^{\circ} \mathrm{C}$ for one hour. Results for the I/S fibers prepared at the extrusion temperatures of 230 and $250^{\circ} \mathrm{C}$ are shown.

$190{ }^{\circ} \mathrm{C}$, the fiber structure was dominated by the SCcrystals as shown in Fig. 10. Degree of orientation of the SC-crystals was relatively low for the take-up velocity of up to $3 \mathrm{~km} / \mathrm{min}$. When the spinning speed was increased, the fibers consisting of highly oriented SC-crystals were obtained. In some samples, for example $8 \mathrm{~km} / \mathrm{min}$ fibers with the extrusion temperature of $250{ }^{\circ} \mathrm{C}$, a small amount of highly oriented $\alpha$-form crystals was also detected. At this moment, it was speculated that the non-systematic appearance of the $\alpha$-form crystals was due to the inevitable difference in cooling condition after the annealing at $190{ }^{\circ} \mathrm{C}$. If the fibers were cooled down rather slowly after the annealing, there can be an additional formation of the $\alpha$-form crystals during the cooling procedure.

\subsubsection{Birefringence measurement}

Interference fringe patterns of the $\mathrm{C} / \mathrm{S}$ fibers before and after the annealing observed under the interference microscope are compared in Fig. 11 "M"shaped fringe patterns observed for the as-spun fibers indicated that the orientation degrees of the sheath and core parts exhibited significant difference, whereas fringe pattern of ordinary "Oval" shape for the annealed fibers suggested that the degrees of orientation of core and sheath parts were similar.

Birefringence of the annealed fibers is shown in Fig. 12. After the annealing of the $\mathrm{C} / \mathrm{S}$ fibers at $120{ }^{\circ} \mathrm{C}$, birefringence of both sheath and core components

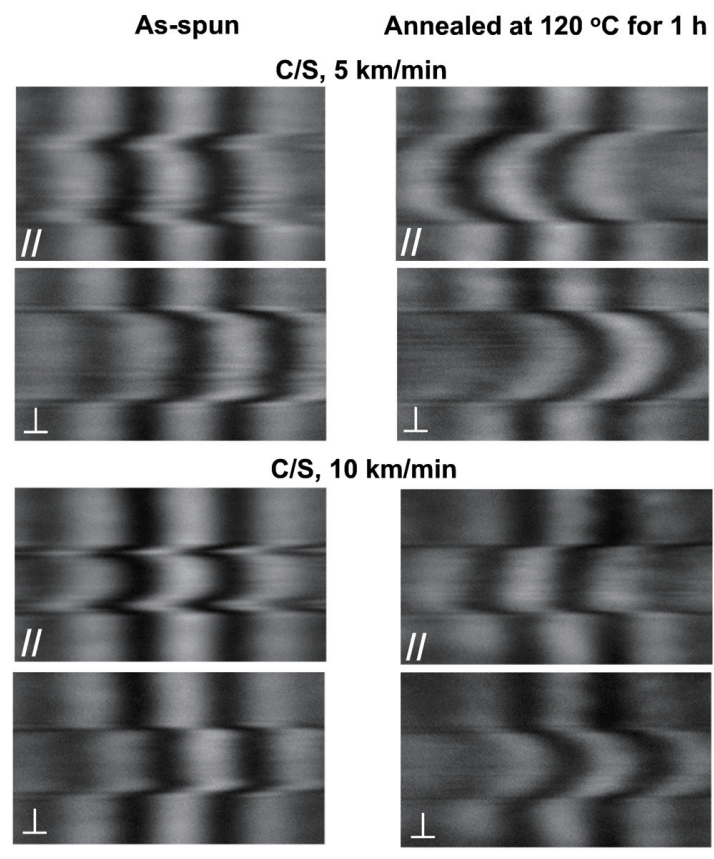

Fig. 11 Interference fringe patterns of the as-spun and annealed $\mathrm{C} / \mathrm{S}$ fibers prepared at two different take-up velocities. Extrusion temperature and annealing temperature are $230{ }^{\circ} \mathrm{C}$ and $120{ }^{\circ} \mathrm{C}$. The fringe patters were observed under an interference microscope equipped with a polarizing filter in the directions parallel and perpendicular to the fiber axis.

increased in the low take-up velocity region in comparison with the as-spun fibers, which were in an amorphous state. In the high take-up velocity region birefringence of the sheath part, PLLA, did not show 

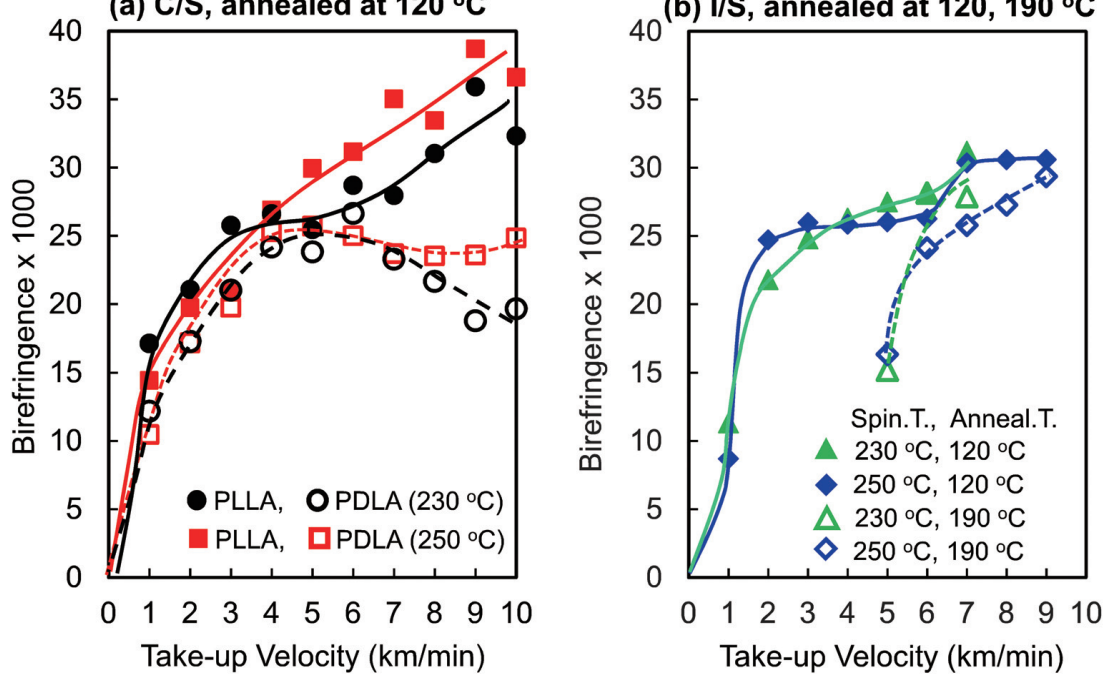

Fig. 12 Variations of birefringence with take-up velocity for (a) sheath (PLLA) and core (PDLA) components of the annealed $\mathrm{C} / \mathrm{S}$ fibers with the extrusion temperatures of 230 and $250{ }^{\circ} \mathrm{C}$, and annealing temperature and time of $120^{\circ} \mathrm{C}, 1 \mathrm{~h}$, and for (b) I/S fibers prepared with the extrusion temperatures of 230 and $250{ }^{\circ} \mathrm{C}$, and annealing temperatures of 120 and $190^{\circ} \mathrm{C}$. For figure (a), closed and open symbols correspond to the PLLA and PDLA, respectively, whereas red and black symbols correspond to the extrusion temperatures of 230 and $250{ }^{\circ} \mathrm{C}$, respectively. For figure (b) closed and open symbols correspond to the annealing temperatures of 120 and $190{ }^{\circ} \mathrm{C}$, whereas green and blue symbols correspond to the extrusion temperatures of 230 and $250{ }^{\circ} \mathrm{C}$, respectively.

distinct change whereas that of the core part, PDLA, increased significantly. Especially in the case of fibers prepared with the extrusion temperature of $230{ }^{\circ} \mathrm{C}$, even though the core part of the as-spun fibers prepared at 8 to $10 \mathrm{~km} / \mathrm{min}$ exhibited the birefringence values close to zero, birefringence of the core parts in the annealed fibers increased to sufficiently high values. In general, it can be said that a significant birefringence increase was accompanied by the crystallization in the annealing process.

After the annealing of the $\mathrm{I} / \mathrm{S}$ fibers at $120{ }^{\circ} \mathrm{C}$, birefringence increased significantly in the low takeup velocity region whereas there was not much effect of annealing on birefringence for the fibers prepared at high take-up velocities. The effect of annealing on the change in birefringence was similar for the $\mathrm{C} / \mathrm{S}$ and I/S fibers. When the annealing temperature was raised to $190{ }^{\circ} \mathrm{C}$, birefringence measurement was not possible for the low speed-spun fibers because the fibers were adhered each other. On the other hand, annealing of the as-spun I/S fibers was possible for the fibers prepared above $6 \mathrm{~km} / \mathrm{min}$, the take-up velocities where the orientation - induced crystallization of the fibers proceeded significantly in the spin-line. Birefringence was intact or only slightly decreased for the extrusion temperatures of 230 and $250{ }^{\circ} \mathrm{C}$, respectively. In other words, the conversion of crystalline structure from the $\alpha$-form crystal to the
SC-crystal was achieved without sacrificing the degree of molecular orientation.

\section{Mutual diffusion of PLLA and PDLA}

It should be noted that the $\alpha$-form crystals are composed of either PLLA or PDLA molecules, whereas the SC-crystals are composed of the 1:1 mixture of PLLA and PDLA molecules. The conversion of crystalline structure from the $\alpha$-form crystals to the SC-crystals suggested that the mutual diffusion of the PLLA and PDLA molecules proceeded during the annealing process. For the change in the crystalline modification from the $\alpha$-form crystals to the SC-crystals, diffusion distance of the size of crystallites is necessary. On the other hand, for the cross-section of the I/S fibers consisting of PDLA islands and PLLA sea components, much larger diffusion distance is required.

Assuming that the cross-sectional configuration of the islands and sea components in the spinning pack can be transcribed to that of the as-spun fibers, variations of the diameter of island fibers and the total perimeter length of the islands per unit area with the increase of take-up velocity were estimated as shown in Fig. 13. The distance between the neighboring two islands is about 1.22 times of the island diameter. From this figure, considering the island diameter of 


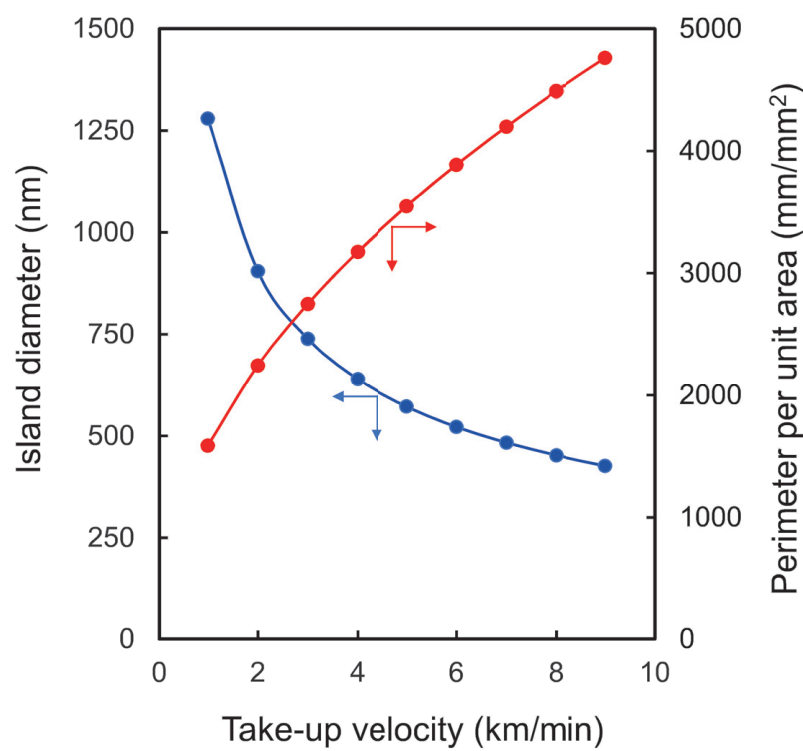

Fig. 13 Variations of the island diameter and the total perimeter of islands per unit area with the increase of take-up velocity for the I/S spinning. The values were estimated from the diameter of the as-spun fibers and the cross-sectional configuration of the I/S fibers shown in Fig. 1.

around $500 \mathrm{~nm}$ at the take-up velocities of 5 to $9 \mathrm{~km} /$ min, it can be said that the diffusion distance in the range of several hundred nanometers per hour was necessary for the sufficient mutual diffusion of the PDLA and PLLA molecules to form a large amount of SC-crystals.

Relation between the diffusion coefficient $D$, the diffusion distance $L$ and the time $t$ for the mutual diffusion at the interface of two polymers can be described as $L^{2} \cong D t$. Assuming the diffusion distance $L$ of $100 \mathrm{~nm}$ and diffusion time of $1 \mathrm{~h}, D$ was roughly estimated to be around $3 \times 10^{-14} \mathrm{~cm}^{2} / \mathrm{s}$. Fundamental researches on the evaluation of $D$ values have been conducted for the interfaces between different polymers. The reported values vary depending on the polymer combinations and measurement temperature. For example, utilizing the experimental techniques of ellipsometry, forward recoil spectrometry, rheometry, and confocal Raman spectroscopy, Yukioka [41], Kim [42], Qiu [43], and Hu [44], respectively, reported the diffusion coefficient values in the range of $10^{-16}-10^{-13}$ $\mathrm{cm}^{2} / \mathrm{s}$. From these semi-quantitative estimations, it can be concluded that the mutual diffusion of the PLLA and PDLA molecules to form sufficiently large amount of SC-crystals is possible in our experimental conditions.

Following the above discussion, mutual diffusion of PLLA and PDLA during the extrusion process and possible formation of the SC crystals during the extrusion process need to be considered especially for the I/S spinning at the extrusion temperature of 230 ${ }^{\circ} \mathrm{C}$. For the promotion of the mutual diffusion during the extrusion, positive factor is the higher temperature and negative factor is the larger crosssectional size. If there is an effective mutual diffusion even in the extrusion process for the spinning of I/S fibers, it may cause the difficulty of extrusion and lowering of spinnability in comparison with the $\mathrm{C} / \mathrm{S}$ fibers because of the development of SC crystals.

\section{Conclusions}

With the aim of producing polylactide fibers consisting of highly oriented SC crystals, high-speed bicomponent melt spinning of the I/S fibers consisting of PLLA and PDLA as the sea and island components, respectively, was carried out. For comparison, bicomponent spinning of the core-sheath $(\mathrm{C} / \mathrm{S})$ fibers consisting of PLLA and PDLA as the sheath and core components was also performed. Molecular orientation of the as-spun fibers increased with the increase of take-up velocity. For the $\mathrm{C} / \mathrm{S}$ fibers, orientation-induced crystallization of the higher molecular weight component, PLLA, started from the take-up velocity of around 4 or $5 \mathrm{~km} / \mathrm{min}$. There was a significant orientation relaxation of the lower molecular weight component, PDLA, with the further increase of take-up velocity. Development of only homo-crystals was confirmed through the wide-angle $\mathrm{X}$-ray scattering analysis of the as-spun $\mathrm{C} / \mathrm{S}$ and $\mathrm{I} / \mathrm{S}$ fibers. On the other hand, in the DSC analysis of the I/ $\mathrm{S}$ fibers, along with the melting peak of homo-crystals, distinct melting peak of the SC crystals was observed. This result suggested the significant mutual diffusion of PLLA and PDLA molecules during the DSC analysis. Post-annealing of the as-spun fibers revealed that the high-speed spun I/S fibers could maintain their shapes after the annealing at $190{ }^{\circ} \mathrm{C}$, the temperature higher than the melting temperature of homo crystals, if the orientation - induced crystallization proceeded in the spinning process. After the annealing, fibers consisting of a large amount of highly oriented SC crystals could be formed successfully, indicating that the diameter of the island fibers was small enough for the efficient mutual diffusion of PLLA and PDLA molecules in the fiber cross-section. 


\section{References}

1. Q. Qin, W. Takarada, and T. Kikutani, J. Fiber Sci. Tech., 73(2), 49 (2017).

2. W. Hoogsteen, A. R. Postema, A. J. Pennings, G. T. Brinke, and P. Zugenmaier, Macromolecules., 23(2), 634 (1990).

3. H. Tsuji, and Y. Ikada, J. Appl. Polym. Sci., 53(8), 1061 (1994).

4. $\quad$ P. De Santis, Biopolymers., 6(3), 299 (1968).

5. H. Tsuji, and Y. Ikada, Macromol. Chem. Phys., 197 (10), 3483 (1996).

6. X. Jiang, Y. Luo, X. Tian, D. Huang, N. Reddy, and Y. Yang, “Poly(lactic acid)”, R. Auras, L-T. Lim, S. Selke, and H. Tsuji eds., John Wiley \& Sons, USA., 74 (2000).

7. K. Takahashi, D. Sawai, T.Yokoyama, and T. Kanamoto, Polymer., 45(14), 4969 (2004).

8. H. Wang, J. Zhang, and K. Tashiro, Mcromolecules, 50, 3285 (2017).

9. T. Y. Cho, and G. Strobl, Polymer, 47, 1036 (2006).

10. B. Gupta, N. Revagade, and J. Hilborn, Prog. Polym. Sci., 32(4), 455 (2007).

11. O. Avinc, and A. Khoddami, Fibre Chem., 41, 391 (2009).

12. M. Puchalski, S. Kwolek, G. Szparaga, M. Chrzanowski, and I. Krucinska, Polymers., 9(1), 1 (2017).

13. M. Takasaki, H. Ito, and T. Kikutani, J. Macromol. Sci. Part B., 42(3\&4), 403 (2003).

14. H. Tsuji, Macromol. Biosci., 5, 569 (2005).

15. Y. Furuhashi, Y. Kimura, N. Yoshie, and H. Yamane, Polymer., 47, 5965 (2006).

16. D. Masaki, Y. Fukui, K. Toyohara, M. Ikegame, B. Nagasaka, and H. Yamane, Fiber., 64, 212 (2008).

17. K. Hemmi, G. Matsuba, and H. Tsuji, J. Appl. Crystallogr., 47(1), 14 (2014).

18. Z. C. Zhang, Z. H. Sang, and Y. F. Huang, ACS Sustain. Chem. Eng., 5(2), 1692 (2017).

19. Z. Xiong, G. Liu, and X. Zhang, Polymer., 54(2), 964 (2013).

20. P. Pan, L. Han, J. Bao, Q. Xie, G. Shan, and Y. Bao, J. Phys. Chem. B., 119(21), 6462 (2015).

21. Y-F. Huang, Z-C. Zhang, and Y. Li, Cryst. Growth. Des., 18(3), 1613 (2018).

22. S. H. Kim, J. P. K. Tan, F. Nederberg, K. Fukushima, Y. Y. Yang, R. M. Waymouth, and J. L. Hedrick, Macromolecules, 42, 25 (2009).
23. R.Y. Bao, W. Yang, X.F. Wei, B.H. Xie, and M. B. Yang, ACS Sustain. Chem. Eng., 2, 2301 (2014).

24. L. Cui, Y. Wang, and Y. Guo, Polym. Adv. Technol., 27, 1301 (2016).

25. Z. Jing, X. Shi, and G. Zhang, Polymers., 9(3), 107 (2017).

26. X. Li, X. Zhang, and G. Liu, RSC $A d v$., 8, 28453 (2018).

27. H. Bai, H. Liu, and D. Bai, Polym. Chem., 5, 5985 (2014).

28. T. Biela, A. Duda, and S. Penczek, Macromolecules, 39, 3710 (2006).

29. M. Kakuta, M. Hirata, and Y. Kimura., J. Macromol. Sci. Part-C., 49, 107 (2009).

30. H. Uehara, Y. Karaki, S. Wada, and T. Yamanobe, ACS Appl. Mater. Interfaces., 2, 2707 (2010).

31. Y. Ikada, K. Jamshidi, H. Tsuji, and S-H. Hyon, Macromolecules, 20(4), 904 (1987).

32. J. R. Sarasua, N. L. Rodriguez, A. L. Arraiza, and E. Meaurio, Macromolecules, 38, 8362 (2005).

33. X. Wang, and R. E. Prud'homme, Macromol. Chem. Phys., 212, 691 (2011).

34. P. E. Le Marec, L. Ferry, and J. C. Quantin, Polym. Degrad. Stab., 110, 353 (2014).

35. T. Kikutani, J. Radhakrishnan, and S. Arikawa, $J$. Appl. Polym. Sci., 62(11), 1913 (1996).

36. J. Radhakrishnan, T. Kikutani, and N. Okui, Text. Res. J., 67, 684 (1997).

37. X. Q. Shi, H. Ito, and T. Kikutani, Polymer., 47, 611 (2006).

38. J. Shimizu, N. Okui, and T. Kikutani, High-Speed Fiber Spinning, A. Ziabicki, H. Kawai eds., Wiley Interscience., 173 (1985).

39. M. Takasaki, N. Fukushi, M. Yoshizawa, S. Onosato, M. Hanada, W. Takarada, Y. Kawahara, T. Kikutani, H. Kobayashi, and K. Tanaka, J. Macromol. Sci. Part-B., 56, 143 (2017).

40. J.shao, S. Xiang, X. Bian, J. Sun, G. Li and X. Chen, Ind. Chem. Res., 54, 2246 (2015).

41. S. Yukioka, K. Nagato, and T. Inoue, Polymer., 33, 1171 (1992).

42. E. Kim, E. J. Kramer, W.C. Wu, and P. D. Garrett, Polymer., 35, 5706 (1994).

43. H. Qiu, and M. Bousmina, Macromolecules, 33, 6588 (2000).

44. C. Hu, X. Chen, J. Chen, W. Zhang, and M. Q. Zhang, Soft Matter., 8, 4780 (2012). 